\title{
Implementation of Peltier Tiles for Heating Jacket
}

\author{
Fitria Hidayanti, Erna Kusuma Wati, Risad Anwar
}

\begin{abstract}
Peltier modules or Peltier tiles utilize the Seebeck phenomenon, where a semi-conductor thermocouple material is flanked by 2 plates, if one side is hot and the other side is cold, the module will produce a voltage whose value is proportional to the temperature difference. This effect can be applied in reverse. If the module is electrified, it will produce heat on one side and cold on the other side. Jacket as a heater is applied when the ambient temperature is lower than the body temperature. The temperature of the heating jacket is $53.1^{\circ} \mathrm{C}$. In the experiment $6000 \mathrm{mAh}$ battery can provide power for Peltier for 35 minutes.

Keywords: Peltier tiles, heating jackets, Seebeck phenomenon, application, body temperature.
\end{abstract}

\section{INTRODUCTION}

Peltier tile is a device that uses a peltier effect to produce hot or cold conditions that can be applied to coolers or heaters [1]. If the peltier module or peltier tile is electrified, it will produce heat on one side and cold on the other [2]. Therefore, by utilizing the Peltier module as its heating element, it is hoped that it can maintain body temperature under normal conditions of $36.5{ }^{\circ} \mathrm{C}$. The lowest temperature makes the human body uncomfortable. Maintain body temperature to remain in normal conditions around $36.5^{\circ} \mathrm{C}$. The purpose of this research in producing a heating jacket with peltier tiles appropriate to maintain body temperature in a low-temperature environment with peltier tiles as a heat source with a $3000 \mathrm{mAh}$ battery power source.

Peltier element or Peltier tiles is a tool that works according to the Peltier Effect [3, 4]. In 1821, J. T. Seebeck who first discovered the phenomenon where two metal plates are different and connected, and there is the cold temperature on one side, and the other side is hot, the object will produce a small voltage. This effect is referred to as the Seebeck Effect $[5,6]$. Working principle of this device has two sides when a DC flows through the device, it carries heat from one side to the other, so that one side gets cold while the other gets hotter. The hot side will be attached with a heatsink so that it stays at room temperature, while the cold side goes below room temperature [7]. The Peltier tiles structure was shown in Fig. 1.

Revised Manuscript Received on March 13, 2020.

* Correspondence Author

Fitria Hidayanti*, Engineering Physics Department, Universitas Nasional, Jakarta, Indonesia. Email: fitriahidayanti@gmail.com

Erna Kusuma Wati, Engineering Physics Department, Universitas Nasional, Jakarta, Indonesia.

Risad Anwar, Engineering Physics Department, Universitas Nasional, Jakarta, Indonesia.

(c) The Authors. Published by Blue Eyes Intelligence Engineering and Sciences Publication (BEIESP). This is an open access article under the CC BY-NC-ND license (http://creativecommons.org/licenses/by-nc-nd/4.0/)

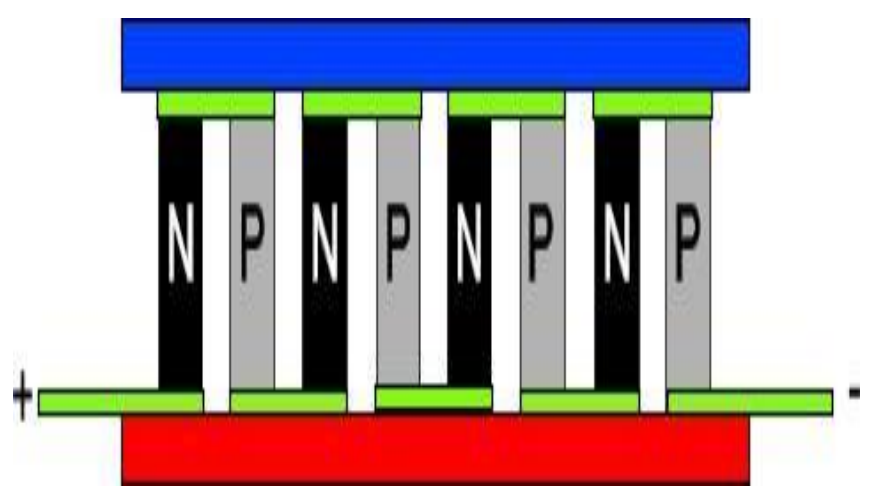

Fig. 1.Peltier Tiles Structure [7]

Peltier tiles construction consists of p-type and n-type semiconductor materials. This p-type and n-type pair is called a thermocouple. In the Peltier module, there are hundreds of thermocouples connected in series with each other and connected in parallel on the two plates. Two different semiconductors, one n-type and one p-type are used because they must have different electron densities [8]. The main advantage of peltier coolers when compared with the pressure and evaporation technology is the absence of moving parts or rotating liquid, so that it has a long life span and strong against leakage, has a small size, and a form that is easily adjusted [9].

\section{MATERIALS AND METHOD}

\section{A. Materials}

The tools used in making the prototype of the heating jacket as follows.
a. Peltier Module TEC-12706
b. AWT IMR18650 6000mAh Li-ion battery
c. XL6009 Voltage Regulator
d. Jacket
e. Sanwa Digital Multimeter
f. T1110 Digital Thermometer
g. Copper Cable
h. Kapton Tape 2 "
i. Aluminum Tape
j. Solder Dekko 40 Watt

\section{B. Design of Heater Jackets}

Design of heater jackets was shown in Fig. 2. 


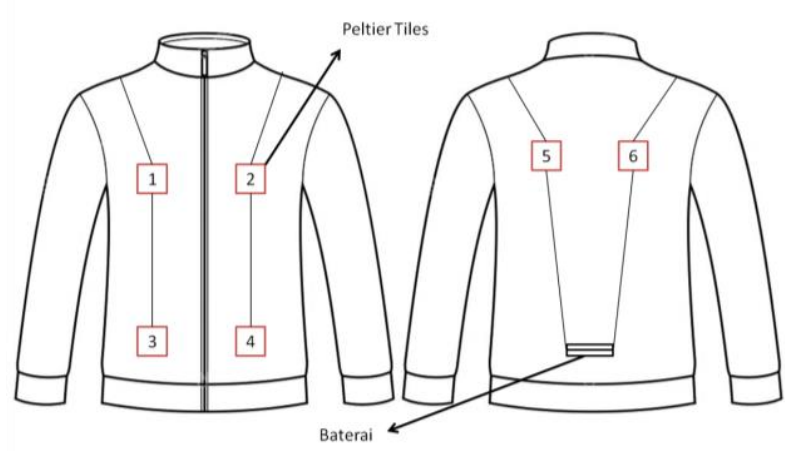

Fig. 2. Heater Jacket Design

Heaters installed on the jacket as 6 pieces, i.e. 2 pieces on the back, 2 pieces on the chest, and 2 pieces heaters on the waist pocket. Each heater and energy source is installed in parallel to get heat higher. The arrangement of the circuit can be seen in Fig. 3 below.

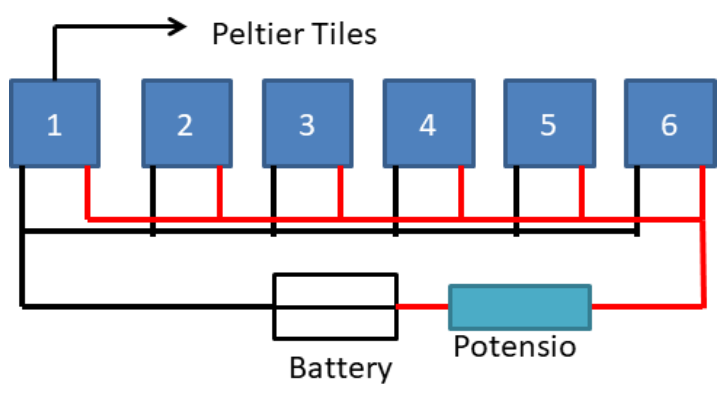

Fig. 3. Heating Circuit Scheme

The voltage source for the heater circuit comes from the battery. The battery used is the type of Li-ion IMR with a size of 18650. This type of battery was chosen because of the resulting performance and commonly used. This battery is capable of producing high current output and has a high energy capacity. XL6009 Converter is a DC-DC converter module with a function to change the input voltage to a higher output voltage. The output voltage can be adjusted by turning the trim pot (pretension). Kapton tape (Polyimide Tape) is a tape made from polyimide to withstand hot temperatures ranging between $-169{ }^{0} \mathrm{C}$ and $200{ }^{0} \mathrm{C}$. Aluminium tape is a good duct tape as a conductor of temperatures from $-50{ }^{0} \mathrm{C}$ to $150{ }^{\circ} \mathrm{C}$. Solder for welding components with lead. Digital thermometer to measure the temperature of the peltier when given a DC voltage. Multimeter to measure the voltage and resistance of a circuit.

\section{RESULTS AND DISCUSSION}

The heating element is a peltier tiles module which has a resistance of 8 ohms per unit. Six peltier tiles are arranged in parallel so that the resistance shown on the multimeter was 3.43 ohms. This condition occurred due to the measurement included a connecting cable among the peltier tiles in the jacket, which has resistance. A battery that has been charged for 3 hours can provide energy for the heating circuit for 35 minutes in continuous use. Voltage issued by the battery is constant every second that is equal to $3.25 \mathrm{~V}$. The battery consists of 2 batteries arranged in parallel. With the initial jacket temperature condition of $27{ }^{\circ} \mathrm{C}$, a continuous increase in temperature occurs. There is a little increase in temperature until it reaches a peak temperature of $41.5^{\circ} \mathrm{C}$. Then the jacket temperature tends to be stable and does not cause a decrease in temperature continuously. The ideal temperature of $39^{\circ} \mathrm{C}$ is reached in 3 minutes and 40 seconds. The temperature on the surface of the peltier reaches $53.1{ }^{\circ} \mathrm{C}$. The simulation carried out in an air-conditioned room with a temperature of $18^{\circ} \mathrm{C}$.

\section{Power on the Heater Jacket}

The amount of power needed to meet the needs of the heating jacket to reach the ideal temperature, experiments were carried out using a potentiometer and a Peltier module. The circuit arranged with an additional potentiometer between the battery and the Peltier module. With a thermometer, pay attention to the circuit that has turned on until it reaches a stable temperature. Then adjust the potentiometer so that the thermometer shows the ideal temperature of $39^{\circ} \mathrm{C}$. Measuring the voltage and current flow in the Peltier module.

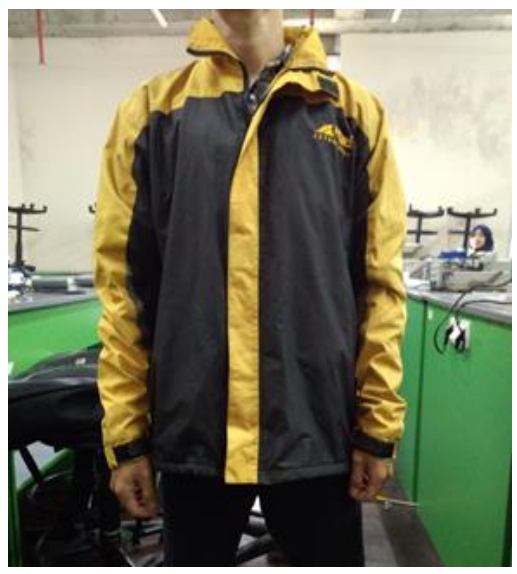

(a)

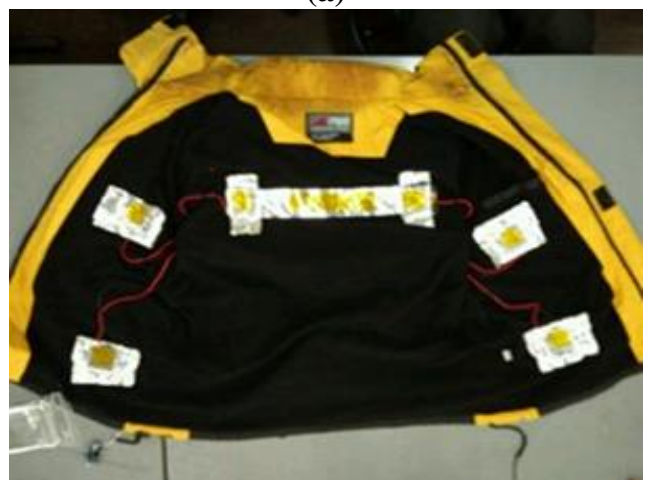

(b)

Fig. 4. Heating Circuit Scheme

(a) Outer heater jacket (b) Inner heater jacket

Heater jacket in this research is the development of outdoor jackets that have been widely circulated showed in Fig. 4. Maximum warmth was provided for users in low-temperature environments. This jacket is equipped with a Peltier Module and used as a heater and powered by two Li-ion batteries that can be recharged. Six Peltier Tiles were used. Two pieces placed on the left and right back, and two pieces on the left and right chest, and two pieces on the waist pocket.

This placement was determined due to the body part releases much heat into the environment, i.e. the back and chest. This condition held to provide warmth to the abdomen and hands when putting the hand in a pocket.

Blue Eyes Intelligence Engineering \& Sciences Publication

(C) Copyright: All rights reserved.

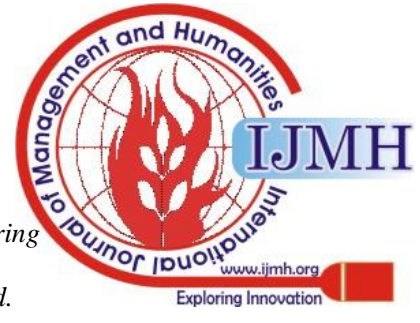


From the experiments to determine the amount of power needed to turn on the heating jacket, the power needed for a Peltier module is 1.125 Watt. Six Peltier modules in the heating jacket circuit need 6.75 Watt for lighting. This amount of power can be borne by the batteries used in this research. With batteries used, the number of Peltier modules used in the circuit can still be added to increase the warmth of the jacket. The circuit also needs to be added to the potentiometer circuit to regulate the amount of power.

\section{CONCLUSION}

Peltier modules can be used as heaters on a heating jacket according to the design. The temperature produced by Peltier is measured with a digital thermometer is $53.1{ }^{\circ} \mathrm{C}$. Therefore we need an intermediate media for Peltier and human skin so that the heat generated can be evenly distributed throughout the body, thus it is more efficient. An additional potentiometer circuit is also needed to regulate and protect the battery so that the battery can last longer because it releases the power as needed and does not exceed $39^{\circ} \mathrm{C}$. In this experiment, a fully charged battery can power the heater for 35 minutes. Power as 6.75 Watt is needed.

\section{ACKNOWLEDGMENT}

Thank you for Lembaga Penelitian dan Pengabdian kepada Masyarakat (LPPM) Universitas Nasional and my collegues in Faculty of Engineering and Science, Universitas Nasional.

\section{REFERENCES}

1. Ajiwiguna, T.A., R. Nugroho, and A. Ismardi. Method for sthermoelectric cooler utilization using manufacturer's technical information. in AIP Conference Proceedings. 2018. AIP Publishing.

2. Casano, G. and S. Piva, Experimental investigation of the performance of a thermoelectric generator based on Peltier cells. Experimental Thermal and Fluid Science, 2011. 35(4): p. 660-669.

3. Flipse, J., et al., Direct observation of the spin-dependent Peltier effect. Nature nanotechnology, 2012. 7(3): p. 166.

4. Harman, T., J. Cahn, and M. Logan, Measurement of thermal conductivity by utilization of the Peltier effect. Journal of Applied Physics, 1959. 30(9): p. 1351-1359.

5. Uchida, K., et al., Observation of the spin Seebeck effect. Nature, 2008. 455(7214): p. 778.

6. Xiao, J., et al., Theory of magnon-driven spin Seebeck effect. Physical Review B, 2010. 81(21): p. 214418.

7. Totala, N., et al., Study and fabrication of thermoelectric air cooling and heating system. Int J Eng Invent, 2014. 4: p. 20e30.

8. Nesarajah, M. and G. Frey. Thermoelectric power generation: Peltier element versus thermoelectric generator. in IECON 2016-42nd Annual Conference of the IEEE Industrial Electronics Society. 2016. IEEE.

9. Vidhya, D., et al., Peltier Module for Theremoelectric Heating and Cooling.

\section{AUTHORS PROFILE}

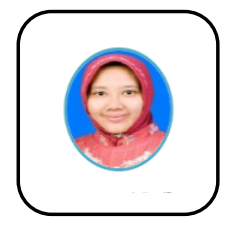

Fitria Hidayanti, Ph.D. candidate at Faculty of Engineering, University of Indonesia. She obtained her bachelor degree at Bandung Institute of Technology, Indonesia and master degree at University of Indonesia. Currently. She is an Assistant Professor at Engineering Physics Department, Universitas Nasional, Jakarta, Indonesia.

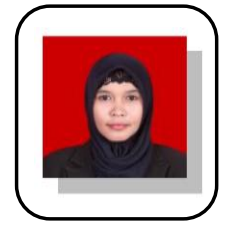

Erna Kusuma Wati, She obtained her bachelor degree in Physics Education from the Yogyakarta National University, Indonesia. She completed her master degree in Physics at Gadjah Mada University. Currently, she is an Assistant Professor at Universitas Nasional, Jakarta, Indonesia.

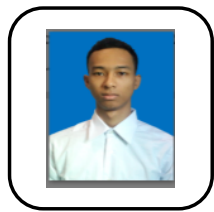

Risad Anwar He obtained Bachelor Degree at Engineering Physics Department, Universitas Nasional, Jakarta, Indonesia.

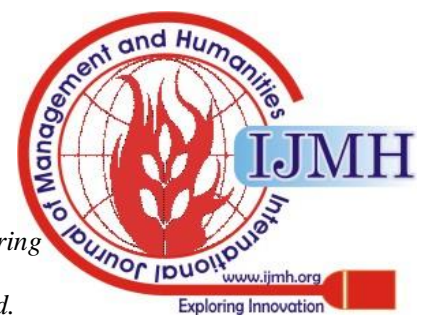

